Vol. 16, Núm. 2

Abr.-Jun. 2020. pp 96-102 doi: $10.35366 / 94539$

https://dx.doi.org/10.35366/94539

\title{
Consideraciones legales ante la pandemia por COVID-19
}

\author{
Legal considerations in the face of the COVID-19 Pandemic
}

\author{
José Luis Martínez Guevara, * Abraham Amuid Dávila Rodríguez ${ }^{\ddagger}$
}

* Cirujano Ortopedista y Traumatólogo, Coordinador del Comité de Medicina Legal.
‡Licenciado en Derecho. Asesor Legal.

Federación Mexicana de Colegios de Ortopedia y Traumatología, A.C. FEMECOT.

Correspondencia: Dr. José Luis Martínez Guevara. Edificio Médico de Especialistas. EME, Calle Hidalgo No. 2532, despacho \# 303m, Col. Obispado, 64060, Monterrey, Nuevo León. Correo electrónico: martinezj@ @hotmail.com

\section{RESUMEN}

COVID-19 fue declarada una emergencia de salud pública de preocupación internacional por la OMS el 30 de enero de 2020, y en México el 24 de marzo de 2020 por el Consejo General de Salud. El Artículo 29 de la Constitución Mexicana menciona que en caso de contingencia sanitaria el Presidente: podrá restringir en el país los derechos por un tiempo limitado. Sin suspenderse los derechos universales. Al final de la restricción quedarán sin efecto. Se suspende: libertad de tránsito, ejercicio profesional (no aplica a profesionales de la salud) a reunirse. No podemos negar nuestros servicios. La penalidad a la que estamos expuestos se describe en los artículos 470, 471 y 472 de la Ley General de Salud. Los hospitales públicos y privados continuarán con sus funciones habituales. Seguridad: artículo 132.- Obligaciones de los patrones: proporcionará a los trabajadores los instrumentos necesarios para su trabajo y capacitarlos. Ante la agresión y discriminación que sufre el personal de salud y los pacientes, la fuerza pública del estado protege a los hospitales y médicos. De acuerdo con la CONAPRED se debe evitar la discriminación de los pacientes y personal de salud en su entorno. Evitar conflictos legales con base en un buen expediente clínico. Firmar el consen-

\section{ABSTRACT}

COVID-19 was declared a Pandemic by 30 January 2020 by the World Health Organization (WHO), Mexico on 24 March 2020. Article 29 Mexican constitution, in the event of a health contingency, the President: may restrict rights in the country for a limited time. Without suspending universal rights. At the end of the contingency they will be void. Suspended: Freedom of transit, professional exercise. (Health Professionals No), to meet. We do not deny our services. The penalty to which we are exposed is described in Articles 470, 471 and 472 of the General Health Law. Public and private hospitals will continue their usual functions. Safety: Article 132.- Employers' obligations: Provide workers with the necessary tools for their work and train them. In the face of the aggression and discrimination suffered by health personnel and patients, the state public force protects hospitals and doctors. According to CONAPRED, discrimination against patients and health personnel in their environment should be avoided. Avoid legal conflicts based on a good clinical record. Sign informed consent. Stick to bioethical principles, especially in resuscitation maneuvers. Telephone 
timiento informado. Apegarse a los principios bioéticos, sobre todo en las maniobras de resucitación. Las consultas telefónicas, telemedicina y redes sociales son frecuentes en esta contingencia, informarles que es una orientación y no una consulta presencial, no existe una vinculación legal. Recordar que estamos creando un expediente electrónico y debemos conservarlo por cinco años. Es ético cobrar nuestros honorarios. El derecho de objeción de conciencia no aplica.

Palabras clave: Pandemia COVID-19, emergencia sanitaria, derechos y obligaciones del médico, expediente clínico, telemedicina. consultations, telemedicine and social networks are frequent in this contingency, informing them that it is an orientation and not a face-to-face consultation, there is no legal linkage. Remember that we are creating an electronic file and must keep it for five years. It is ethical to collect our fees. The right of conscientious objection does not apply.

Keywords: COVID-19 pandemic, health emergency, physician's rights and obligations, clinical record, telemedicine.

\section{¿QUÉ ES UNA PANDEMIA?}

La Organización Mundial de la Salud califica como pandemia una nueva enfermedad que se propaga a nivel mundial.

La epidemia por COVID-19 fue declarada una emergencia de salud pública de preocupación internacional por la OMS el 30 de enero de 2020 y como epidemia el 11 de marzo del presente año.

\section{¿QUÉ ES UN ESTADO DE CONTINGENCIA SANITARIA? CONSTITUCIÓN POLIITICA DE LOS ESTADOS UNIDOS MEXICANOS (CEUM) ${ }^{1}$}

Artículo 29. En los casos de perturbación grave de la paz pública, el Presidente de los Estados Unidos Mexicanos, con la aprobación del Congreso de la Unión, podrá restringir o suspender en todo el país o en lugar determinado el ejercicio de los derechos y las garantías para hacer frente a la situación; pero deberá hacerlo por un tiempo limitado. En los decretos que se expidan no podrá restringirse ni suspenderse el ejercicio de los derechos universales de las personas.

Cuando se ponga fin a la restricción o suspensión del ejercicio de los derechos y garantías, todas las medidas legales y administrativas adoptadas durante su vigencia, quedarán sin efecto de forma inmediata.

\section{¿QUÉ GARANTÍAS PUEDEN SUSPENDERSE O RESTRINGIRSE?}

Libertad de tránsito, estado de queda, libertad de trabajo y ejercicio profesional (excepto para los profesionales de la salud), derecho a reunirse y evitar contagios.

No se restringe: lo relacionado con la salud (hospitales, insumos médicos, etcétera), industrias prioritarias, medios de comunicación y transporte. Derecho de petición y amparo.

Salud, triage, amparo.

Se requiere: declaración del estado y sea publicada en el Diario Oficial de la Federación (DOF). 


\section{¿QUÉ PASA SI ME NIEGO A ATENDER A LOS PACIENTES?}

\section{Ley General de Salud (LGS)2}

Artículo 469.- Al profesional de la atención médica que sin causa justificada se niegue a prestar asistencia a una persona, en caso de notoria urgencia, se le impondrá de seis meses a cinco años de prisión y multa de cinco a 125 días de salario mínimo y suspensión para ejercer la profesión hasta por dos años. Si se produjere daño por la falta de intervención, será suspensión definitiva para el ejercicio profesional.

Artículo 470.- Siempre que en la comisión de cualquiera de los delitos previstos participe un servidor público, además de las penas a que se haga acreedor, se le destituirá del cargo y se le inhabilitará para ocupar otro similar.

\section{Código Penal Federal (CPF) ${ }^{3}$}

Artículo 215.- Cometen el delito de abuso de autoridad los servidores públicos que incurran en alguna de las conductas siguientes: cuando indebidamente retarde o niegue a los particulares la protección o servicio que tenga obligación de otorgarles o impida la presentación o el curso de una solicitud.

\section{OBLIGACIONES DE MI SEGURIDAD}

Artículo 132.- Son obligaciones de los patrones:

- III. Proporcionar oportunamente a los trabajadores los útiles, instrumentos y materiales necesarios para la ejecución del trabajo.

- XV. Proporcionar capacitación y adiestramiento a sus trabajadores.

- XVI. Instalar y operar las fábricas, bajo el reglamento y las normas oficiales mexicanas en materia de seguridad, salud y medio ambiente.

- XIX. Proporcionar a sus trabajadores los medicamentos profilácticos.

- XIX BIS. Cumplir con las disposiciones que en caso de emergencia sanitaria fije la autoridad sanitaria.

Artículo 189.- Código Penal Federal.

Al que cometa un delito en contra de un servidor público, al ejercer lícitamente sus funciones o con motivo de ellas, se le aplicará de uno a seis años de prisión. Recordar que el personal de salud que labora en el IMSS y el ISSSTE se consideran empleados federales.

\section{Reglamento de la Ley General de Salud, prestación de servicios de atención médica (RLGMPSAM)}

Artículo 26.- Los establecimientos que presten servicios de atención médica contarán para ello con los recursos físicos, tecnológicos y humanos que señale este Reglamento y las normas técnicas que al efecto emita la Secretaría. 


\section{RESPONSABLE SANITARIO}

Artículo 19.- Corresponde a los responsables llevar a cabo las siguientes funciones:

- I. Establecer y vigilar el desarrollo de procedimientos para asegurar la oportuna y eficiente prestación de los servicios que el establecimiento ofrezca.

- II. Vigilar que se apliquen las medidas de seguridad e higiene para la protección de la salud del personal expuesto por su ocupación.

- V. Informar, a las autoridades sanitarias competentes, de las enfermedades de notificación obligatoria.

Artículo 21.- En los establecimientos donde se proporcionen servicios de atención médica, deberá contarse, de acuerdo a las Normas Técnicas correspondientes, con personal suficiente e idóneo.

\section{¿QUÉ ACCIONES TENGO CONY SIN CONTINGENCIA?}

Juicio de Amparo.

Reclamación en la Comisión Nacional de los Derechos Humanos (CNDH).

\section{OBLIGACIONES DEL HOSPITAL}

Artículo 35.- Cuando en un establecimiento para la atención médica se presente algún demandante de servicios que padezca alguna enfermedad infectocontagiosa será motivo de notificación obligatoria, deberá referirlo de inmediato al servicio correspondiente a fin de que dicha persona tenga el mínimo contacto con los usuarios.

\section{SI EL PROFESIONAL DE LA SALUD ENFERMA}

Artículo 36.- El personal que preste sus servicios en algún establecimiento de atención médica, en ningún caso podrá desempeñar sus labores si padece alguna de las enfermedades infectocontagiosas, ello es motivo de notificación obligatoria.

\section{TODOS LOS HOSPITALES (PRIVADOS)}

Artículo 71.- Los establecimientos públicos, sociales y privados que brinden servicios de atención médica para el internamiento de enfermos están obligados a prestar atención inmediata a todo usuario en caso de urgencia que ocurra en la cercanía de los mismos.

Decreto por el que se declaran acciones extraordinarias en las regiones afectadas de todo el territorio nacional en materia de salubridad general para combatir la enfermedad grave de atención prioritaria generada por el virus SARS-CoV-2 (COVID-19). ${ }^{4}$ 


\section{Diario Oficial de la Federación (DOF), 27 de marzo de 2020}

Artículo segundo. Para efectos del artículo anterior, la Secretaría de Salud podrá implementar de manera inmediata, además de lo previsto en el artículo 184 de la Ley General de Salud, las acciones extraordinarias siguientes:

- I. Utilizar como elementos auxiliares todos los recursos médicos y de asistencia social de los sectores público, social y privado existentes en las regiones afectadas y en las colindantes.

- II. Adquirir todo tipo de bienes y servicios, a nivel nacional o internacional.

\section{HOSPITALES PRIVADOS}

En el sector privado continuarán laborando las empresas y todos aquellos que resulten necesarios para hacer frente a la contingencia: hospitales, clínicas, farmacias, laboratorios, servicios médicos.

\section{OBLIGACIONES DE LOS PACIENTES}

Artículo segundo. Las medidas preventivas que los sectores público, privado y social deberán poner en práctica son las siguientes:

a) Evitar la asistencia a centros de trabajo, espacios públicos y otros lugares concurridos a los adultos mayores de 65 años o más, personas con riesgo de enfermedad grave y/o morir. Embarazadas o en periodo de lactancia, menores de cinco años, personas con discapacidad, personas con enfermedades crónicas no transmisibles, o con algún padecimiento o tratamiento farmacológico que les genere supresión del sistema inmunológico. Además, se deberá cumplir las medidas básicas de higiene.

\section{¿LES DEBO SEGUIR PAGANDO A MIS EMPLEADOS?}

Las relaciones laborales se mantendrán y aplicarán conforme a los contratos individuales, colectivos, contratos ley o Condiciones Generales de Trabajo que correspondan, durante el plazo al que se refiere el presente Acuerdo y al amparo de la Ley Federal del Trabajo y la Ley Federal de los Trabajadores al Servicio del Estado reglamentaria del Apartado B del Artículo 123 Constitucional.

Suspender temporalmente y hasta nuevo aviso de la autoridad sanitaria los eventos masivos, las reuniones y congregaciones de más de 100 personas.

\section{¿CÓMO REALIZAR LA ATENCIÓN A LOS PACIENTES?}

Debemos de realizar la atención médica con los principios habituales de acuerdo con la Norma Oficial Mexicana NOM-024-SSA3-2012, ${ }^{5}$ y de los protocolos establecidos en las unidades médicas para la selección de pacientes COVID positivos 
o negativos. Se deberá de registrar todas las acciones y eventos, indicando la fecha y la hora del suceso. Es mandatorio que se nos proporcione y que usemos el equipo de protección personal de acuerdo al área en que nos encontremos laborando, especialmente cuando se generen aerosoles y en el manejo de vías respiratorias (intubación).

Con el advenimiento de la tecnología de información y comunicación, la atención de la población que se encuentre en riesgo y confinada en sus domicilios se hará por telemedicina. De acuerdo a la Norma Oficial Mexicana NOM24-SSA3-2012, ${ }^{6}$ haciendo hincapié que la exploración física no se realizará, a excepción de que aquella consulta a distancia se encuentre participando otro médico (consulta especializada). Lo mismo sucede con las redes sociales (WhatsApp), en las que todo queda registrado, por lo tanto, estamos creando un expediente clínico electrónico, que por ley deberá de guardarse por cinco años. Existen plataformas digitales especializadas en telemedicina, con sistema integrado de cobro de los honorarios médicos, lo cuales, por cierto, es lícito y ético cobrarlos.

\section{¿QUÉ CIRUGÍAS PUEDO REALIZAR?}

No existe ningún inconveniente legal para realizar cirugías. Deberán tener prioridad las urgencias relativas a la vida o a la función de una extremidad, fracturas expuestas, procesos infecciosos o actividad tumoral; dejando las cirugías electivas para tiempos posteriores. Se debe evitar riesgos innecesarios.

\section{PRINCIPIOS DE BIOÉTICA EN LA PANDEMIA}

Aunque nos encontremos inmersos en una pandemia no debemos olvidar los principios de bioética en relación a la atención y toma de decisiones médicas trascendentales que, con el debido apoyo de un comité especializado, será de gran utilidad para el profesional de la salud.

No debemos de olvidar la relación médico-paciente, además de respetar íntegramente los Derechos Humanos del paciente como de los profesionales de la salud.

\section{PRINCIPIOS A LA NO DISCRIMINACIÓN}

El Consejo Nacional para la Prevención de la Discriminación (CONAPRED), por medio de la Ley Federal para prevenir y eliminar la discriminación:

Artículo 2.- Corresponde al Estado promover las condiciones para que la libertad y la igualdad de las personas sean reales y efectivas. Los poderes públicos federales deberán eliminar aquellos obstáculos que limiten en los hechos su ejercicio e impidan el pleno desarrollo de las personas, así como su efectiva participación en la vida política, económica, cultural y social del país.

Artículo 4.- Para los efectos de esta Ley se entenderá por discriminación toda distinción, exclusión o restricción que, basada en el origen étnico o nacional, 
sexo, edad, discapacidad, condición social o económica, condiciones de salud, embarazo, lengua, religión, opiniones, preferencias sexuales, estado civil o cualquier otra, tenga por efecto impedir o anular el reconocimiento o el ejercicio de los derechos y la igualdad real de oportunidades de las personas.

En nuestro país se han dado brotes aislados de intolerancia hacia el personal de salud, que por el solo hecho de portar ropa propia de la profesión, los estigmatiza como portadores de la enfermedad o incluso en el trasporte público les niegan el servicio. De la misma forma cuando los conocidos o vecinos de una persona que resulta como caso positivo para COVID-19, incluyendo a sus familiares, también han sufrido actos discriminatorios.

Ante esta situación la CONAPRED ha establecido canales de denuncia adecuados y a las autoridades civiles para protegerlos, lo que ha ocasionado la implementación de medios de transporte exclusivo para el personal de salud.

Es necesario comentar que cadenas comerciales mexicanas han establecido acciones de reconocimiento a estos héroes anónimos.

\section{BIBLIOGRAFÍA}

1. Decreto por el que se modifica la denominación del Capítulo I del Título Primero y reforma diversos artículos de la Constitución Política de los Estados Unidos Mexicanos (Internet), Bethesda (MD): México. Diario Oficial de la Federación; La Comisión Permanente del Honorable Congreso de la Unión; cited 2011; 2011 Jun 10, (Citado 2011-06-10). Disponible en: https://www.dof.gob.mx/nota_detalle.php?co digo $=5194486 \&$ fecha $=10 / 06 / 2011$.

2. Decreto de la promulgación de la ley general de salud. (Internet). México. Diario Oficial de la Federación; H. Congreso de la Unión; c1984. 1984 Feb 07, (Citado 1984-07-02). Disponible en: http://www.dof.gob. $\mathrm{mx} /$ nota_detalle.php?codigo=4652777\&fecha=07/02/1984.

3. Decreto por el que se reforma el encabezado de Capítulo I del Título Decimoctavo y se adiciona el artículo 284 Bis al Código Penal Federal (Internet). México. Diario Oficial de la Federación; El Congreso General de los Estados Unidos Mexicanos; c2017. 2017 Jun 22, (Citado 2017 Junio 22). Disponible en: http://www.dof.gob.mx/nota_detalle.php?codigo=5487717\&fecha=22\%2F06\%2F2017.

4. Decreto por el que se declaran acciones extraordinarias en las regiones afectadas de todo el territorio nacional en materia de salubridad general para combatir la enfermedad grave atención prioritaria generada por el virus SARS-CoV2. (COVID 19), (Internet). México. Diario Oficial de la Federación; c2020; 2020 Mar 27, (Citado 2020-03-27). Disponible en: https://www.dof.gob.mx/nota_detalle.php?c odigo $=5590673 \&$ fecha $=27 / 03 / 2020$.

5. PROYECTO de Modificación de la Norma Oficial Mexicana NOM-168-SSA1-1998, Del expediente clínico, para quedar como PROY-NOM-004-SSA3-2009, Del expediente clínico (Internet). México. Diario Oficial de la Federación; c2010. 2010 Oct 05, (Citado 2010-10-05). Disponible en: http://www. dof.gob.mx/normasOficiales/4168/Salud1/Salud1.htm.

6. NORMA Oficial Mexicana NOM-024-SSA3-2012, Sistemas de información de registro electrónico para la salud. Intercambio de información en salud (Internet). México. Diario Oficial de la Federación c2011; 2011 Nov 30, (Citado 2011-11-30). Disponible en: http://dof.gob.mx/nota_detalle.php?codigo=528084 $7 \&$ fecha $=30 / 11 / 2012$.

7. Mendoza-Romo M, Nava-Zárate N, Escalante-Pulido J. "El Médico y la Ley”. Aspectos Éticos y Legales del Consentimiento Informado en la práctica e investigación médica. Gac Méd Méx. 2003; 139 (2): 184-187. Disponible en: https://www.medigraphic.com/pdfs/gaceta/gm-2003/gm032o.pdf.

8. Ley Federal para Prevenir y Eliminar la Discriminación (Internet) México. Diario Oficial de la Federación; c2003; 2003 Jun 11, (Citado 2003-06-11). Disponible en: http://www.diputados.gob.mx/LeyesBiblio/ pdf/262_210618.pdf. 